See Article page 362 .

\section{Commentary: Why should we classify damage control in cardiac surgery?}

\author{
Rune Haaverstad, MD, PhD, a,b \\ Solveig Moss Kolseth, $\mathrm{MD}, \mathrm{PhD},{ }^{\mathrm{a}}$ and \\ Vegard S. Ellensen, MD, $\mathrm{PhD}^{\mathrm{a}}$
}

The concept of damage control surgery (DCS) is less established in cardiac surgery compared with other surgical specialties. This, and the fact that critical cardiovascular incidents are closely related to fatality, DCS might be a less-intuitive choice of strategy. Hence, the paper of Misfield and colleagues ${ }^{1}$ published in the Journal should be warmly welcomed.

DCS in cardiac surgery ought to be distinguished from the usual urgent and emergent procedures that require imminent final solutions. It should rather be regarded as a specialty tool to avoid early mortality and secure a good prognosis for patients in particularly demanding situations. Categorizing clinical situations as type A and $\mathrm{B}$ with subcategories may be meaningful, as these account for a clear distinction between the primary spontaneous situations and the secondary, possibly avoidable, complications.

By proposing this DCS classification for use in cardiac surgery, a potential for improved clinical awareness and new surgical strategies is unveiled. This can prove beneficial in numerous cardiac and aortic catastrophes that place a lot of pressure on the surgeons. Severe bleeding must be stopped immediately, by either open surgery or endovascu-

\footnotetext{
From the ${ }^{\text {a Section }}$ of Cardiothoracic Surgery, Department of Heart Disease, Haukeland University Hospital; and ${ }^{\mathrm{b}}$ Department of Clinical Science, Faculty of Medicine, University of Bergen, Bergen, Norway.

Disclosures: The authors reported no conflicts of interest.

The Journal policy requires editors and reviewers to disclose conflicts of interest and to decline handling or reviewing manuscripts for which they may have a conflict of interest. The editors and reviewers of this article have no conflicts of interest.

Received for publication Sept 28, 2021; revisions received Sept 28, 2021; accepted for publication Oct 6, 2021; available ahead of print Oct 9, 2021.

Address for reprints: Rune Haaverstad, MD, PhD, Department of Heart Disease, Haukeland University Hospital, Jonas Lies vei 65, 5021 Bergen, Norway (E-mail: rune. haaverstad@helse-bergen.no).

JTCVS Techniques 2021;10:367-8

2666-2507

Copyright (c) 2021 The Author(s). Published by Elsevier Inc. on behalf of The American Association for Thoracic Surgery. This is an open access article under the CC BY-NC-ND license (http://creativecommons.org/licenses/by-nc-nd/4.0/).

https://doi.org/10.1016/j.xjtc.2021.10.005
}

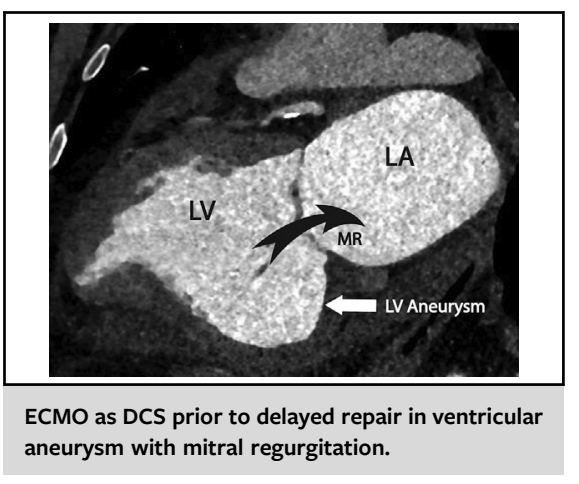

CENTRAL MESSAGE

Damage control surgery saves lives and deserves implementation within cardiac surgery. The classification system may highlight relevant scenarios, improve bailout solutions, and facilitate research.

lar intervention, but the final repair should in many cases be delayed. This enables the stabilization of physiological or hematologic parameters as pointed out in the referred paper, but can also buy enough time for more specialized or experienced surgeons to be involved in the subsequent surgery.

Categorization of different DCS types may be useful in education and research, but regular use of the different terms is unlikely to happen. In type A2a, it has become well-established clinical practice that acute percutaneous coronary intervention is the best immediate treatment to deal with culprit coronary lesions. The delayed treatment option is still a matter of discussion and research, although coronary surgery has robust scientific evidence and superior long-term survival.

Severe bleedings, hemodynamic instability, and infection may all be eligible situations for DCS in cardiac surgery. Transmural myocardial infarction with development of a large left ventricular aneurysm causing acute severe mitral regurgitation with cardiogenic shock is a typical example where a strategy for type A2b situation may be required (Figure 1). In this example emergency venoarterial extracorporeal membrane oxygenation may stabilize the clinical 


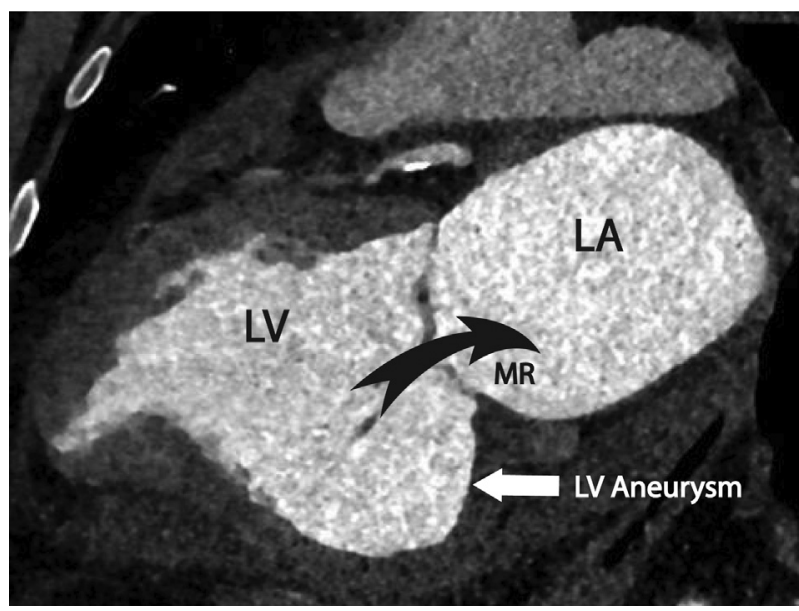

FIGURE 1. Extracorporeal membrane oxygenation as damage control surgery before delayed repair in ventricular aneurysm with mitral regurgitation. $L V$, Left ventricle; $L A$, left atrium; $M R$, mitral regurgitation. situation temporarily to counteract lactic acidosis, backward failure, and pulmonary edema before delayed open surgery with combined mitral and ventricular aneurysm surgery.

Other typical DCS situations most cardiac surgeons will encounter are type B situations with iatrogenic injuries from surrounding tissues with severe bleeding. In some of these situations, one may benefit from immediate hemostasis and rather delay the final surgery.

A focus on surgical risk stratification, damage control, and bailout solutions are of utmost importance in cardiac surgery. However, the clinical applicability of the DCS classification presented by Misfield and colleagues still needs to be tested in future studies.

\section{Reference}

1. Misfield M, Bannon PG, Borger MA, Yan TD. Damage control in cardiac surgery: knowing when to come back another day. J Thorac Cardiovasc Tech. 2021;10: $362-6$. 